\title{
Effect of surface nanocrystallization on corrosion behaviour of coated steel in chloride solution
}

\author{
Liuyan Zhang ${ }^{*}$, Shuimei Yang, Huishu Wu, Xiaohua Jie ${ }^{*}$, Xiaoye Huang, Xiujin Wang \\ School of Materials and Energy, Guangdong University of Technology, Guangzhou 510006, PR China \\ *E-mail: zlyjust@gdut.edu.cn
}

doi: $10.20964 / 2018.04 .09$

Received: 20 November 2017 / Accepted: 18 January 2018 / Published: 6 March 2018

\begin{abstract}
A nanocrystalline (NC) layer was fabricated on the surface of the low-alloy steel 15CrMo using highenergy shot peening. Two kinds of conversion coatings including the chemical conversion coating and electrochemical conversion coating were separately prepared on the surface of the original coarsegrained (CG) and the NC steel. The morphology and corrosion behavior of the different conversion coatings on the $\mathrm{CG}$ and $\mathrm{NC}$ surface were evaluated. The results indicated that after surface nanocrystallization of $15 \mathrm{CrMo}$ steel, the main changes due to the chemical conversion coating on its surface were the amorphization of the regular crystallized particles and more alloy elements in the film. The film formation characteristics of the electrochemical conversion coating did not change as much. The chemical conversion coating on the NC steel had higher corrosion resistance than that on the CG steel due in large part to the self-passivation elements joining in the film and the dense structure of the film. However, the electrochemical conversion coating on the NC steel had higher corrosion resistance than that on the CG steel due to its stronger adhesion to substrate. Surface nanocrystallization of the steel substrate can effectively improve the corrosion resistance of the conversion coating.
\end{abstract}

Keywords: nanocrystalline; steel; conversion coating; morphology; corrosion resistance

\section{FULL TEXT}

(C) 2018 The Authors. Published by ESG (www.electrochemsci.org). This article is an open access article distributed under the terms and conditions of the Creative Commons Attribution license (http://creativecommons.org/licenses/by/4.0/). 